Conclusions Results highlight a variety of psychosocial variables that influence STD screening uptake and preferred methods of screening. Our findings provide further evidence for the need to tailor the development of STD screening and treatment options that are acceptable to asymptomatic men in traditionally underserved areas.

\section{P4.018 "JUST ONE THING ON THE PLATE"-VIEWS OF COMMUNITY MEMBERS AND PROVIDERS ON SEXUAL HEALTH SERVICES IN THE FORT MCPHERSON AREA OF SOUTHWEST ATLANTA: FINDINGS FROM A RAPID ETHNOGRAPHIC ASSESSMENT}

doi:10.1136/sextrans-2013-051184.0916

K Kroeger, S Willilams, C Alexander-Pender, J Ford, V Vasani. Centers for Disease Control and Prevention, Atlanta, GA, United States

Background The neighbourhoods surrounding Fort McPherson in southwest Atlanta, GA are in transition due to closure of the Fort in 2011 and pending redevelopment. Health services in the area are in transition due to budget cuts and changes to the US health system. Neighborhoods surrounding the Fort have some of the highest STD rates in the US. The objective of this assessment was to obtain community member and provider views on available services for sexual health, and potential changes to services as a result of redevelopment and health system changes.

Methods We carried out 35 in-depth interviews with representatives from 23 health and social service agencies and 12 community residents in July 2012. A checklist of available sexual and reproductive health services was administered to 18 agencies. Qualitative and checklist data were analysed using OSR's NVivo 8 and MS Excel.

Results Providers and community members perceived that affordable, accessible options for sexual health care in the neighbourhoods adjacent to the Fort had severely declined in recent years, due to economic pressures and neighbourhood deterioration. Providers stressed the need for more holistic models of health care that address a range of client health and psychosocial needs, in addition to sexual health. While sexual health services are available within 5 miles of the Fort, there are significant social and structural barriers that may prevent community members from using them, including lack of awareness of existing services, cost, transportation barriers, stigma, and geographic and social isolation.

Conclusions Reaching vulnerable populations with sexual health services will continue to be challenging even as the US health system evolves. Nesting sexual health services within a broader array of health and social services, and developing stronger linkages and referral networks between STD programmes and other agencies may improve reach to those who most need these services.

\section{P4.019 SOCIAL DETERMINANTS THAT IMPROVE ACCESS TO PREVENTION AND TREATMENT OF HIV AND STI IN MACEDONIA}

doi:10.1136/sextrans-2013-051184.0917

\begin{abstract}
1.2R Krastovska, 'M Stevanovic. ' Clinic for Infectious Diseases and Febrile Conditions, Skopje, Macedonia; ${ }^{2}$ H.E.R.A., Skopje, Macedonia
\end{abstract}

Background There is no clear and in-depth statistics about STI among the Macedonian population. There is no comprehensive Clinic for STI in the country. Our objectives are to identify social factors associated to lower STI screening, and to examine availability of data related to HIV and STI in Macedonia.

Methods A descriptive analysis of information and a quantitative study have been undertaken, using official reports, national researches and documents in the period 2002-2012.
Results Epidemiological reports show significant data for HIV/AIDS.

During the period of 11 years, the average HIV/AIDS morbidity have been 0.3 per 100.000 , with availability to different characteristics of HIV/AIDS situation in Macedonia. These data are currently available only from two referent institutions in Macedonia (Clinic for Infectious Diseases and Institute for Public Health). On the other hand, there are numerous shallow and insufficient information on other STI. The average morbidity with other STI: Syphilis -0.1, Gonorrhea -0.2 , Chlamydia -3.0 , Hepatitis C -3.9 , and Hepatitis C 8.7. Available data on basic STI characteristics does not exist. All the information have been received from the District Public Health Centers, by collecting data from different health providers in the country. Patients have fear and prejudice to discuss openly their sexuality, sexual attitudes and STI, which implies that patients 'refuse to go to the doctor, they take antibiotics on their own hand, or delay visiting doctors until their health situation becomes heavily deteriorated. Consequently, this leads to imprecise diagnostics and keeping them distant from the relevant institutions.

Conclusion HIV/AIDS morbidity is greater than the one with other STI diseases (like syphilis and gonorrhoea). Establishment of unique services that treat all STI would render clear and precise information on the factual epidemiological picture of all STI in Macedonia and would promote confidence depiction and stigma overcome with patients.

\section{P4.020 ANALYSES OF SOCIAL NETWORK CHARACTERISTICS OF DRUG ADDICTS IN METHADONE MAINTENANCE TREATMENT (MMT) CLINIC IN YUNNAN, CHINA}

doi:10.1136/sextrans-2013-051184.0918

J P Zhang, C Kangyongbo, W Sunjiayi. School of Public Health of Kunming Medical University, Kunming, China

Purpose The aim is to examine the effects of social networks characteristics of drug addicts in MMT clinics, to promote HIV/AIDS spread control.

Method In the first stage targeted sampling method will be used, 144 patients will be sampled in outpatient in MMT clinics. In the second stage 20 people drawn from the 144 patients will be randomly sampled and the social network nomination method employed with investigating individual network nomination.

Results The proportion of female drug addicts has increased over the past 10 years. The average length of drug injection history is 12.68 years. Surveys show that HIV infections among this group are more frequently increasing in Yunnan than in other provinces of China. The proportion of single people differs from that of the married people $\left(\mathrm{X}^{2}=9.242, \mathrm{P}<0.017\right)$. The syringe reuse, syringe cleaning and needle sharing are statistically significant to the infection with HIV $(\mathrm{P}<0.01)$. The "key persons" characteristic of the social network, have a certain influence over the network members. The centre network analysis of 22 individuals indicated that the maximum network size of individual drug use group members was 6 persons, and the minimum network size was 3 persons.

Conclusion For the prevention of risky behaviours in the high-risk groups, the past experience from other countries should be taken into account. Cutting off the transmission ways is regarded as leading method, but should be combined with comprehensive prevention measures. It is necessary to build good social atmosphere for the control of the spread of HIV/AIDS, to improve the social communication network for the receivers of methadone maintenance treatment, and to extend the network of formal social support groups in order to improve availability of health services information for receivers of methadone MMT, to promote the recovery of social functioning, and to increase social participation of MMT receivers. 